\title{
Evaluation and Prediction of Urban Entrepreneurship Environment in China: A Case of Guangzhou City
}

\author{
Yuxi Kuang1, Yan $\mathrm{Bu}^{2 *}$ \\ ${ }^{1}$ School of Public Administration, Zhuhai College of Jilin University, Zhuhai, China \\ ${ }^{2}$ School of Economics and Management, China University of Geosciences, Wuhan, China \\ Email: *buyan 10@126.com
}

How to cite this paper: Kuang, Y.X. and Bu, Y. (2018) Evaluation and Prediction of Urban Entrepreneurship Environment in China: A Case of Guangzhou City. Journal of Service Science and Management, 11, 414-432.

https://doi.org/10.4236/jssm.2018.114029

Received: June 10, 2018

Accepted: August 17, 2018

Published: August 22, 2018

Copyright $\odot 2018$ by authors and Scientific Research Publishing Inc. This work is licensed under the Creative Commons Attribution International License (CC BY 4.0).

http://creativecommons.org/licenses/by/4.0/

\begin{abstract}
Studying the urban entrepreneurship environment has guiding significance for the development of urban economy and employment. Based on the PSR (Pressure-State-Response) model framework, this paper constructs an index system for evaluation of urban entrepreneurship environment, and uses the multi-factor weighted method to systematically quantitatively analyze and comprehensively evaluate the state of entrepreneurship policies, service systems, and hardware facilities, and use $\operatorname{GM}(1,1)$ model to predict the development trend of urban entrepreneurship environment in Guangzhou. The study shows that the policy measures to optimize the entrepreneurship environment have effectiveness, time lag and accumulation effect, and the government's response measures are the core factors for the stable development of the urban entrepreneurship environment. It is expected that the entrepreneurship environment in Guangzhou will continue to improve in the future. Finally, it is pointed out that optimizing the urban entrepreneurship environment should start from innovation, attracting talents, increasing financial support, and highlighting regional industrial characteristics to form an entrepreneurship economy.
\end{abstract}

\section{Keywords}

PSR Model, Entrepreneurship Environment, GM(1, 1) Model, Guangzhou

\section{Introduction}

Countries around the world are increasingly focusing on entrepreneurship, seeing entrepreneurship as a new driving force for economic development and employment promotion, and innovation drive has also become the core strategy for 
many countries to seek competitive advantage. A large number of economic theory studies and practice have proved that active entrepreneurship activities will bring positive effects such as increased employment and economic growth, thus promoting the development of the entire regional economy. China is the most populous country in the world, and the urbanization process is rapid. China has a large population and limited urban development space. How can we achieve sustainable urban development in a limited urban space in the future? How to promote the increasing employment of the urban population? This is a question worthy of further study and discussion. At present, China's economic development has entered a new normal stage, and promoting "mass entrepreneurship and innovation" has become an extremely important strategic task for promoting economic and social development. From the reality of our country, entrepreneurship activities show huge differences between different cities. There are many reasons for this, such as the location, size, history and culture of the city, the impact on the region, and the economic and social problems they face, but these can be attributed to the entrepreneurship environment.

The entrepreneurship environment refers to the sum of the elements that directly or indirectly affect the entrepreneurship activities of the entrepreneurship entity and their mutual relations. It is an important supporting condition for entrepreneurship activities. For a region or a city, a good entrepreneurship environment is the basis for its development and a symbol of its vitality and competitiveness. The entrepreneurship environment needs to be jointly created by the government and the whole society, and the government plays an irreplaceable leading role. A region or a city should create a differentiated entrepreneurship environment around the characteristics of local development, development direction and characteristics of entrepreneurship activities. At present, some of China's economically and technologically advanced central cities have begun to position the strategic goals of urban development in innovative cities or cities with high-tech industries as the leading industries. Many cities also have state-level high-tech industrial development zones. The various types of science and technology industrial parks at all levels make it necessary to create an entrepreneurship environment around the needs of innovative entrepreneurship activities in a limited area (usually within a city). Therefore, the establishment of an indicator system for urban entrepreneurship environmental assessment will help decision makers to clarify the various factors affecting urban entrepreneurship activities, so as to make decisions that are most conducive to the urban entrepreneurship environment. At the same time, it gives a quantitative evaluation of the pressure, state and response measures faced by the urban entrepreneurship environment, which has reference value for urban economic development and the construction of entrepreneurship environment.

A case of Guangzhou city, this paper first introduces the study state of urban entrepreneurship environment at home and abroad, and then introduces the general situation of entrepreneurship environment in Guangzhou. Then the PSR 
(pressure-state-response) model is proposed to construct the urban entrepreneurship environment evaluation index system, and the applicability of the PSR model is analyzed. Later, the multi-factor comprehensive weighting method and $\mathrm{GM}(1,1)$ model for evaluating and predicting the urban entrepreneurship environment were introduced, and the quantitative evaluation and prediction of the entrepreneurship environment in Guangzhou were made. Finally, the conclusions of this paper and the policy recommendations for the development of urban entrepreneurship environment in Guangzhou are given.

\section{Literature Review}

The urban entrepreneurship environment is decisive for the potential entrepreneurs to invest in entrepreneurship activities and the success of entrepreneurship activities. Therefore, it has become the study focus of academia, and it is also the focus of all levels of government to build a good environment to support innovation-driven development, and promote "mass entrepreneurship, innovation". Compared with other influencing factors of the entrepreneurship environment, culture is the primary influencing factor [1]. Some scholars are paying more attention to the overall study of the entrepreneurship environment, or only to study high-growth entrepreneurship [2] [3] [4]. Rakesh Sambharya et al. use the data from the 43 countries in the Global Entrepreneurship Watch to test the impact of the environment on survival and opportunity-based entrepreneurship, and the perception of the institutional environment has a greater impact on opportunistic entrepreneurship. In comparison, the norm of the institutional environment and the perception of the institutional environment have a significant impact on survival entrepreneurship [5]. Erkko Autio et al. studied the effectiveness of policies on stimulating rapid growth of entrepreneurship. By studying the policy and entrepreneurship development status of the target region for nearly six years, it is considered that the favorable policies have a significant effect on entrepreneurship [6]. Maria Soledad believed that creating a good entrepreneurship environment is conducive to encouraging individual entrepreneurship [7], and he uses a three-factor model to empirically analyze the impact of incubator policies on the development of entrepreneurship firms [8]. Romanelli believed that the availability of resources in the environment affects the survival and development of enterprises, and also affects the ability of new ventures to integrate into the environment [9]. Hammers proposes that a relatively loose entrepreneurship environment can increase the formation rate of enterprises [10]. The five-dimensional model of entrepreneurship environment jointly developed by Gnyawali and Fogel takes into account factors such as financial support, non-financial support, entrepreneurship and management skills training, socio-economic conditions, entrepreneurship policies and procedures [11]. Based on the five-dimensional model, the GEM research framework considers that factors affecting entrepreneurship environmental conditions include financial support, government policies, government programs, education and train- 
ing, research and development transfer, business environment, market openness, physical infrastructure, culture and Social norms, etc. [12]. Cai Li et al. believed that government departments and relevant social organizations exist as the host of the entrepreneurship environment in entrepreneurship, and the entrepreneurship environment must exert its influence on entrepreneurship activities through certain types of entities [13]. Some scholars have conducted empirical research on the entrepreneurship environment of some cities in China and the current situation of entrepreneurship activities in the region, and thus obtained the degree of influence of entrepreneurship activities in the region [14]. Zheng Y. H. et al. conducted study on the effectiveness of financial services technology innovation in the three stages of R \& D investment, achievement transformation and industrial output, and pointed out that financial institutions and various venture capital investment and other innovative financial products should be encouraged, and financing platforms should be improved. The service platform ensures that the technology innovation capital chain and the financial capital chain can be organically combined [15]. Zhang L. W. proposed that the theory of three industry divisions has been difficult to guide the current strategic adjustment of China's national economic structure, and it cannot solve the challenges of promoting economic transformation and upgrading through innovation and entrepreneurship. Therefore, based on the establishment of six industrial theories, it is proposed six times. Industrial theory leads the practice of innovation and entrepreneurship [16]. Pastoral et al. believed that the degree of entrepreneurship activity depends on institutional arrangements. Entrepreneurship is not only influenced by formal systems such as policies and laws, but also by informal institutions such as cultural traditions and public opinion [17].

In summary, the current scholars in the study of entrepreneurship environment evaluation, the empirical research on the urban entrepreneurship environment in China is not rich enough. Although some existing researches are based on the GEM (Global Entrepreneurship Watch) entrepreneurship activity model to evaluate the entrepreneurship environment in certain regions, the GEM model's indicator system has certain flaws in the practice of entrepreneurship activities in China. The system is not fully compatible with the practice of entrepreneurship activities in China. The characteristics of some entrepreneurship activities in China cannot be expressed in the model. Therefore, this paper analyzes the applicability of PSR model in urban entrepreneurship environment evaluation, builds a city entrepreneurship environment evaluation index system based on PSR (Pressure-State-Response) model, and adopts multi-factor comprehensive weighting method to comprehensively evaluate urban entrepreneurship environment. And take Guangzhou as an example for empirical analysis. Based on the evaluation and analysis, the $\operatorname{GM}(1,1)$ model is used to further predict the future development trend of the urban entrepreneurship environment. Therefore, relevant policy recommendations are proposed for optimizing the urban entrepreneurship environment. 


\section{Overview of the Entrepreneurship Environment in Guangzhou ${ }^{1}$}

Guangzhou has formed 10 billion-level industrial clusters for automobile, petrochemical, electronics, electric power production and supply, electrical machinery and equipment manufacturing, wholesale and retail, finance, real estate, leasing and business services, and transportation. The added value of advanced manufacturing industry accounted for $65.6 \%$ of the added value of manufacturing enterprises above designated size. Guangzhou is vigorously implementing the IAB program (new generation information technology, artificial intelligence, biomedicine) and NEM program (new energy, new materials) to build a number of billion-level industrial clusters to create an international technology industry innovation center. Guangzhou is a "model city of China manufacturing 2025".

In 2017, Guangzhou's automobile production reached 3.108 million, and its output ranked first in the country. In 2016, the total output value of Guangzhou's automobile industry reached 434.627 billion yuan, becoming the first pillar industry. In 2017, the business revenue of software and information services in Guangzhou exceeded 300 billion yuan for the first time, an increase of about $18 \%$, and has become one of the pillar industries. In 2017, the added value of the financial industry reached 1998.76 billion yuan, an increase of $8.6 \%$ year-on-year, accounting for $9.3 \%$ of GDP, becoming the fifth pillar industry and the fourth largest economic growth engine in Guangzhou. The scale of intelligent equipment and robot industry in Guangzhou is nearly 50 billion yuan, and the production of robots ranks second in the country. It has formed a complete industrial chain of robots from upstream key components, midstream to downstream systems. The total volume of postal services in Guangzhou exceeded 60 billion yuan, of which 2.867 billion were completed, ranking first in the country. The scale of cross-border e-commerce ranks first in the country.

The economic development capability of Guangzhou headquarters ranks third in China, and it is within the scope of the first-class cities with headquarters economic development. Guangzhou has attracted investors from more than 130 countries and regions around the world to invest and develop trade with more than 220 countries and regions around the world. As of the end of September 2017, a total of 30,000 foreign-invested enterprises have settled in Guangzhou. 297 Fortune 500 companies have established 921 projects in Guangzhou, of which 120 have headquarters or regional headquarters in Guangzhou. More than 3000 Internet companies in Guangzhou have created WeChat, Vipshop, YY Voice, Cool Dog Music, Netease, UC Browser, Tiger Tooth Live, etc. The online game industry revenue in Guangzhou accounts for nearly $30 \%$ of the country.

In 2017, more than 4000 new high-tech enterprises were added in Guangzhou, which is second only to Beijing, with a total of more than 8700. In 2017, the number of patent applications in Guangzhou was 117,332, a year-on-year increase of $33.3 \%$, including 36,941 invention patent applications, an increase of ${ }^{1}$ Data and information come from the Guangzhou Municipal Government Gazette and web data. 
29.5\%; 244 international patent applications, 2441, an increase of $48.7 \%$; the number of invention patents was 9345, Growth of 21.9\%. Guangzhou's hard technology development index ranks in the top three in the country. From January to June 2018, the number of patent applications in Guangzhou reached 85,526, an increase of 52.8\%. The 9 cities of the Pearl River Delta, headed by Guangzhou, will join hands with Hong Kong and Macao to build the Guangdong, Hong Kong and Macau Bay Area and become one of the world's four largest bay areas. Guangzhou was ranked first in the world's fastest growing megacity by the United Nations.

\section{Models and Methods}

\subsection{PSR Model}

\subsubsection{Applicability Analysis of PSR Model}

The PSR is a model proposed by the Organization for Economic Co-operation and Development (OECD) for the analysis of pressure, state, and response of the system. The model is a dynamic model structure. The indicators of Pressure $(\mathrm{P})$, State (S) and Response (R) can cover political, economic, social, cultural and ecological aspects. The model can better display and analyze the development of things in a variety of factors. The following changes and dynamic mechanisms explain why, what, and how to deal with these three aspects. Pressure is the influence of people's activities in the political, economic, and social dimensions; state refers to the change of environmental state and the development of economic society under the influence of pressure factors; response is the current state, government, Social organizations and what decisions people make or take to change the current state and make it better. Specifically, the mechanism of action of these three aspects is "Human production and life behaviors have an impact on the environment. These effects may be positive pressures or negative pressures. Then the environment changes with pressure, showing a certain reality, facing the reality of the environment, the government, Social organizations, etc. will respond accordingly to develop the environmental status in a good direction".

The causal relationship between pressure, state and response within the framework of the PSR model is clear, which can reflect the comprehensive dynamic transmission mechanism and change process of various factors on things, in ecosystem health assessment, urban environmental performance assessment, land intensive use. The research field is widely used.

The entrepreneurship environment is similar to the ecosystem, in which the interaction between the various factor indicators and the entities involved in the entrepreneurship activities and the entrepreneurship environment interacts and is in a dynamic equilibrium. Based on the PSR framework model, the regional economic and social development state will have a positive or negative pressure on the entrepreneurship environment. In response to the pressure of the entrepreneurship environment, government departments and social organizations 
will respond accordingly. Corresponding measures are taken to influence the entrepreneurship environment through response channels, which will have an impact on regional economic and social development. The whole system has the characteristics of dynamic conduction mechanism, forming an organic dynamic cycle, and its action mechanism is shown in Figure 1. Therefore, the PSR model framework can reflect the comprehensive impact mechanism of various factors on the urban entrepreneurship environment, effectively evaluate the state of the urban entrepreneurship environment, and predict the development trend of the future urban entrepreneurship environment in the context of the existing state. The PSR model has applicability to the evaluation of urban entrepreneurship environment.

\subsubsection{Selection of Indicators}

Based on the PSR model framework to build an entrepreneurship environment evaluation index system, it is necessary to separately determine the indicator system of pressure, status and response. In order to truly reflect the entrepreneurship environment of different cities, combined with the research results of the literature [18], follow the evaluation criteria to select the principles of simplicity, measurability, accessibility, reliability and timeliness, based on the comprehensive consideration of China's actual situation, correspondingly Eighteen indicators were selected (in Table 1). The research framework of China's urban entrepreneurship environmental assessment is constructed through comprehensive index, classification index and specific indicators. The research data comes from the Guangzhou Statistical Yearbook (2005-2017) and the Guangdong Statistical Yearbook (2005-2017).

\subsection{Multi-Factor Comprehensive Weighting Method}

\subsubsection{Determination of Indicator Weights}

This paper uses the entropy weight method to calculate the index weights. In information theory, the entropy value reflects the degree of disorder of information,

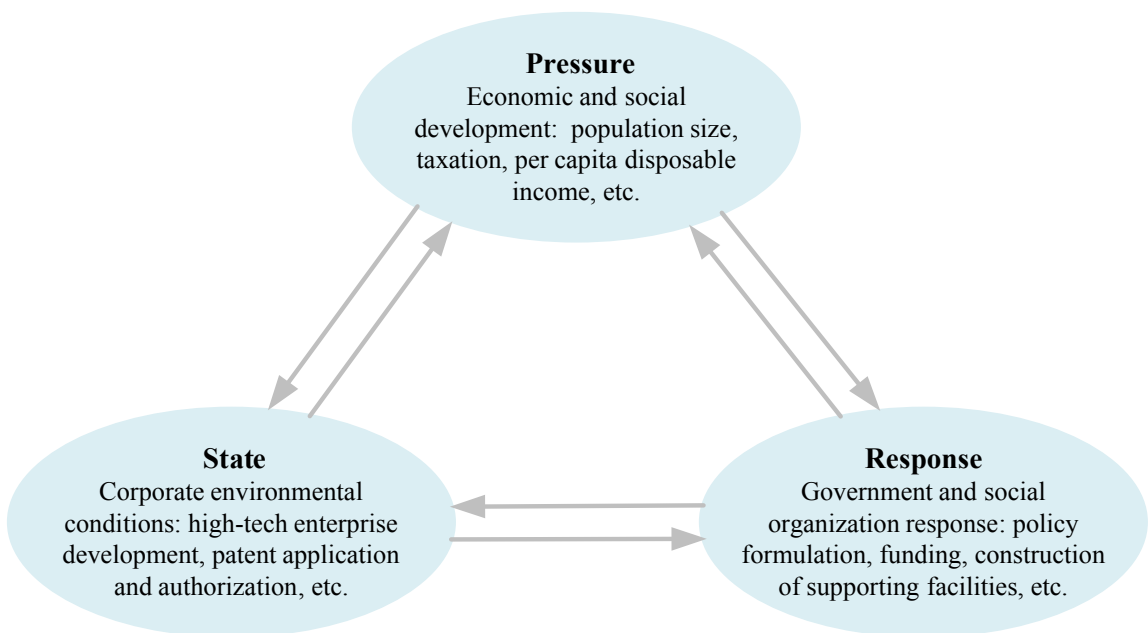

Figure 1. PSR model theory framework. 
Table 1. Pioneering environment evaluation index system based on PSR model.

\begin{tabular}{|c|c|c|c|c|}
\hline Evaluation target & Criteria & Index & Attribute & Number \\
\hline \multirow{18}{*}{$\begin{array}{l}\text { Entrepreneurship } \\
\text { Environmental } \\
\text { Assessment Index } \\
\text { System }\end{array}$} & \multirow{6}{*}{ Pressure } & Resident population & + & $\mathrm{C} 1$ \\
\hline & & City revenue & + & $\mathrm{C} 2$ \\
\hline & & Total fixed assets investment & + & $\mathrm{C} 3$ \\
\hline & & Consumer Price Index $($ Last year $=100)$ & - & $\mathrm{C} 4$ \\
\hline & & $\begin{array}{l}\text { Annual per capita disposable income of urban } \\
\text { residents }\end{array}$ & + & C5 \\
\hline & & $\begin{array}{l}\text { Annual per capita consumption expenditure } \\
\text { of urban residents }\end{array}$ & - & C6 \\
\hline & \multirow{5}{*}{ State } & Total number of high-tech enterprises & + & $\mathrm{C} 7$ \\
\hline & & High-tech industry total output value & + & $\mathrm{C} 8$ \\
\hline & & Patent authorization & + & C9 \\
\hline & & Technical contract turnover & + & $\mathrm{C} 10$ \\
\hline & & Financial institutions loans & + & $\mathrm{C} 11$ \\
\hline & \multirow{7}{*}{ Response } & $\begin{array}{l}\text { Research and experimental development } \\
\text { funding intensity }\end{array}$ & + & $\mathrm{C} 12$ \\
\hline & & Educational expenditure & + & $\mathrm{C} 13$ \\
\hline & & $\begin{array}{l}\text { Research and experimental development } \\
\text { funding supported by government grants }\end{array}$ & + & $\mathrm{C} 14$ \\
\hline & & Social security and employment expenditure & + & $\mathrm{C} 15$ \\
\hline & & Number of air civil routes & + & C16 \\
\hline & & Highway mileage & + & $\mathrm{C} 17$ \\
\hline & & Long-distance cable length & + & $\mathrm{C} 18$ \\
\hline
\end{tabular}

which can be used to measure the amount of information. The more information an indicator carries, the greater the effect of the indicator on decision making. The smaller the entropy value, the smaller the disorder of the system. At present, in order to overcome the uncertainty of the weight of the expert weight method due to different expert experience and review issues, the entropy weight method is often used to determine the weight of each evaluation index. The weight assignment method reduces the subjectivity of the commonly used evaluation methods, and replaces the objective analysis of the data structure with a stronger explanatory power; the method can reflect the difference between the control index and other evaluation indicators, thereby improving the rationality of the evaluation results. . The main calculation steps are as follows:

Step 1 assumes that there are $m$ evaluation objects, and each evaluation object has $n$ indicators, and the original judgment matrix is constructed: $B=\left(x_{i j}\right)_{m \times n}$.

Step 2 Standardize the original data matrix, standardize the original data, eliminate the influence of different units and different metrics between the indicators, in order to obtain the standardized score matrix of each indicator $\bar{R}=\left(r_{i j}\right)_{m \times n}$, Where $r_{i j}$ is the standard value of the $\dot{t}$ th evaluation object on the i-th evaluation index, $r_{i j} \in[0,1]$. 
For positive indicator indicators:

$$
r_{i j}=\frac{x_{i j}-\min \left\{x_{i j}\right\}}{\operatorname{man}\left\{x_{i j}\right\}-\min \left\{x_{i j}\right\}}
$$

For negative indicator indicators:

$$
r_{i j}=\frac{\operatorname{man}\left\{x_{i j}\right\}-x_{i j}}{\operatorname{man}\left\{x_{i j}\right\}-\min \left\{x_{i j}\right\}}
$$

Step 3 Define the entropy of each evaluation indicator:

$$
\begin{gathered}
H_{j}=-\frac{1}{\ln m} \sum_{i=1}^{m} f_{i j} \ln f_{i j} \\
f_{i j}=\left(1+r_{i j}\right) / \sum_{i=1}^{m}\left(1+r_{i j}\right)
\end{gathered}
$$

Step 4 Calculate the entropy weight $w_{j}$ of the $j$-th evaluation index is

$$
w_{j}=\left(1-H_{j}\right) / \sum_{j=1}^{n}\left(1-H_{j}\right)
$$

It can be concluded from the above formula that the smaller the entropy value is, the larger the entropy weight is, indicating that the larger the amount of information corresponding to the evaluation index, the more important the indicator is. Conversely, the larger the entropy value of the indicator, the smaller the entropy weight, indicating that the indicator is less important. The entropy weight method can be used to objectively derive the index weight.

\subsubsection{Determination of the Entrepreneurship Index}

The evaluation indicators are divided into positive indicators and negative indicators. It is assumed that $X_{i}(i=1,2,3, \cdots, n)$ is the actual value of the evaluation index, $S_{i}$ is the arithmetic mean, and $P\left(X_{i}\right)$ is the entrepreneurship index of the indicator. According to the trend of evaluation indicators and the "cask principle", the determination of the entrepreneurship index can be divided into the following two cases:

When the evaluation indicator is a positive indicator:

$$
P\left(X_{i}\right)= \begin{cases}1 & X_{i} \geq 2 S_{i} \\ \frac{X_{i}}{2 s_{i}} & X_{i}<2 S_{i}\end{cases}
$$

When the evaluation indicator is a negative indicator:

$$
P\left(X_{i}\right)= \begin{cases}1 & X_{i} \leq S_{i} \\ 2-\frac{X_{i}}{S_{i}} & S_{i}<X_{i}<2 S_{i} \\ 0 & X_{i} \geq 2 S_{i}\end{cases}
$$

According to the entrepreneurship index and weight value of each indicator, the calculation formula of urban entrepreneurship environment evaluation value is obtained through comprehensive weighting: 


$$
E=\sum_{j=1}^{n} W_{j} \times P_{i j}
$$

$E$ is the evaluation value of the entrepreneurship environment, $W_{j}$ is the weight of the indicator, and $P_{i j}$ is the entrepreneurship index of each indicator.

\subsection{GM(1, 1) Model}

The GM $(1,1)$ model is the basis of gray prediction. The two " 1 " s represent the first-order equation and a variable, respectively, indicating that the model is essentially a univariate first-order differential equation. The model calculation steps are as follows:

Step 1 sets the original sequence $X^{(0)}$ to have $k$ observations:

$$
X^{(0)}=\left\{X^{(0)}(1), X^{(0)}(2), X^{(0)}(3), \cdots, X^{(0)}(k)\right\}
$$

Accumulate the production of a new series $X^{(1)}$ :

$$
X^{(1)}=\left\{X^{(1)}(1), X^{(1)}(2), X^{(1)}(3), \cdots, X^{(1)}(k)\right\}
$$

where: $X^{(i)}(k)=\sum_{i=1}^{k} x^{(0)}(i)$.

Step 2 Use $X^{(1)}$ and $X^{(0)}$ to create matrix $B$ and matrix $Y_{n}$ respectively:

$$
\begin{gathered}
B=\left[\begin{array}{cc}
-\frac{1}{2}\left(X^{(1)}(1)+X^{(1)}(2)\right) & 1 \\
\vdots & \vdots \\
-\frac{1}{2}\left(X^{(1)}(k-1)+X^{(1)}(k)\right) & 1
\end{array}\right] \\
Y_{n}=\left[X^{(0)}(2), X^{(0)}(3), X^{(0)}(4), \cdots, X^{(0)}(k)\right]^{\mathrm{T}}
\end{gathered}
$$

Step 3 According to the matrix $B$ and $Y_{m}$, the parameters $a$ and $b$ are obtained by least squares fitting:

$$
\hat{\alpha}=\left(\begin{array}{l}
a \\
b
\end{array}\right)=\left(B^{\mathrm{T}} B\right)^{-1} B^{\mathrm{T}} Y_{n}
$$

Step 4 The parameters $a, b$ are substituted into the corresponding equation of time:

$$
\hat{X}^{(1)}(k+1)=\left(X^{(0)}(1)-\frac{b}{a}\right) \mathrm{e}^{-a k}+\frac{b}{a}
$$

Step 5 Finds the corresponding function of time (14):

$$
\hat{X}^{(0)}(k+1)=a\left(X^{(0)}(1)-\frac{b}{a}\right) \mathrm{e}^{-a k}
$$

Step 6 Perform a data accumulation and reduction on (15) to obtain the prediction equation:

$$
\hat{X}^{(0)}(k+1)=\hat{X}^{(1)}(k+1)-\hat{X}^{(1)}(k)
$$

Step 7 Residual test, the point-by-point test model predicts the residual of the restored value and the actual value.

Absolute residual sequence: 


$$
\Delta^{(0)}(k)=\left|X^{(0)}(k)-\hat{X}^{(0)}(k)\right|(k=1,2,3, \cdots, n)
$$

Average relative residual:

$$
\begin{gathered}
\bar{\Phi}=\frac{1}{k} \sum_{i=2}^{k} \varphi_{i} \\
\varphi_{i}=\frac{\Delta^{(0)}(k)}{X^{(0)}(k)}
\end{gathered}
$$

Given $\alpha$, when $\Phi<\alpha$ and $\varphi_{i}<\alpha$ are established, the model is called a residual qualified model. The model is excellent when $\alpha=0.001$, the model is qualified when $\alpha=0.05$, and the model is barely qualified when $\alpha=0.1$.

Step 8 Test the statistical characteristics of the residual distribution:

Calculate the standard deviation $S_{1}$ and $S_{2}$ according to $X^{(0)}(k)$ and $\Delta^{(0)}(k)$

$$
\begin{aligned}
& S_{1}=\sqrt{\frac{\sum\left[X^{(0)}(k)-\bar{X}^{(0)}\right]^{2}}{k-1}} \\
& S_{2}=\sqrt{\frac{\sum\left[\Delta^{(0)}(k)-\bar{\Delta}^{(0)}\right]^{2}}{k-1}}
\end{aligned}
$$

Posterior difference ratio $C=\frac{S_{2}}{S_{1}}$, small error probability $p=P\left(\left|\Delta^{(0)}(k)-\bar{\Delta}^{(0)}\right|<0.6745 S_{1}\right)$.

The accuracy test criteria for the $\operatorname{GM}(1,1)$ model are shown in Table 2 .

\section{Empirical Analysis}

\subsection{Evaluation of Guangzhou Entrepreneurship Environmental}

The change in the comprehensive index of the entrepreneurship environment reflects the changes in the entrepreneurship environment in Guangzhou. This paper selects the relevant entrepreneurship environment development data of Guangzhou from 2005 to 2016, and uses the entropy weight method to determine the weight of the evaluation indicators from the three dimensions of "stress-state-response", as shown in Table 3. Calculate the 2005-2016 Entrepreneurship Environment Index of Guangzhou City by multi-factor comprehensive weighting method, as shown in Table 4 .

The trend of the comprehensive index, pressure index, state index and response index of the entrepreneurship environment is shown in Figure 2 and Figure 3. In 2005-2016, the Guangzhou Entrepreneurship Environment Composite Index is on the rise, indicating that during the period of 2005-2016, the entrepreneurship environment in Guangzhou continued to be optimized, which promoted the development of entrepreneurship activities.

The following is an analysis of the changes in the pressure index, state index and response index in the 2005-2016 Guangzhou Entrepreneurship Environmental 
Table 2. $\operatorname{GM}(1,1)$ model accuracy standard.

\begin{tabular}{ccccc}
\hline Accuracy level & Good & Qualified & Barely qualified & Unqualified \\
\hline$C$ & $C \leq 0.35$ & $0.35<C \leq 0.5$ & $0.5<C \leq 0.65$ & $C>0.65$ \\
$p$ & $p \geq 0.95$ & $0.8 \leq p<0.95$ & $0.7 \leq p<0.8$ & $p<0.7$ \\
\hline
\end{tabular}

Table 3. Weight of each evaluation indicator.

\begin{tabular}{cccccccccc}
\hline Indicator number & $\mathrm{C} 1$ & $\mathrm{C} 2$ & $\mathrm{C} 3$ & $\mathrm{C} 4$ & $\mathrm{C} 5$ & $\mathrm{C} 6$ & $\mathrm{C} 7$ & $\mathrm{C} 8$ & $\mathrm{C} 9$ \\
\hline Weights & 0.038 & 0.053 & 0.044 & 0.062 & 0.056 & 0.067 & 0.037 & 0.054 & 0.062 \\
Indicator number & $\mathrm{C} 10$ & $\mathrm{C} 11$ & $\mathrm{C} 12$ & $\mathrm{C} 13$ & $\mathrm{C} 14$ & $\mathrm{C} 15$ & $\mathrm{C} 16$ & $\mathrm{C} 17$ & $\mathrm{C} 18$ \\
Weights & 0.045 & 0.052 & 0.057 & 0.065 & 0.065 & 0.089 & 0.064 & 0.019 & 0.069 \\
\hline
\end{tabular}

Table 4. Entrepreneurship environment index.

\begin{tabular}{cccccccccccccc}
\hline Years & 2005 & 2006 & 2007 & 2008 & 2009 & 2010 & 2011 & 2012 & 2013 & 2014 & 2015 & 2016 \\
\hline $\begin{array}{c}\text { Composite } \\
\text { index } \\
\begin{array}{c}\text { Pressure } \\
\text { State }\end{array}\end{array}$ & 0.357 & 0.405 & 0.429 & 0.456 & 0.486 & 0.521 & 0.558 & 0.596 & 0.638 & 0.687 & 0.742 & 0.796 \\
Response & 0.220 & 0.309 & 0.336 & 0.367 & 0.402 & 0.443 & 0.489 & 0.542 & 0.604 & 0.676 & 0.758 & 0.822 \\
& 0.291 & 0.319 & 0.347 & 0.378 & 0.412 & 0.451 & 0.494 & 0.541 & 0.595 & 0.655 & 0.721 & 0.796 \\
\hline
\end{tabular}

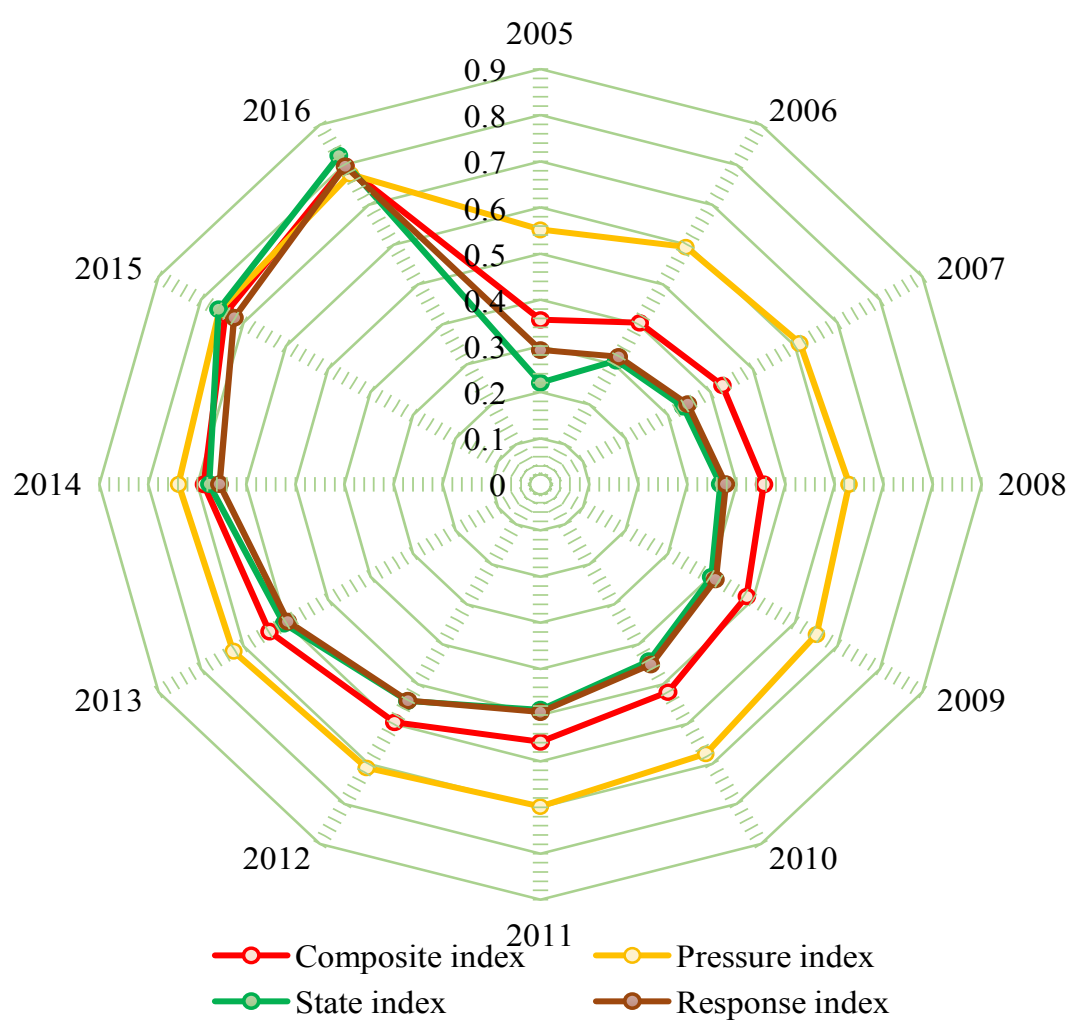

Figure 2. Guangzhou entrepreneurship environment composite index, pressure index, state index, response index radar chart. 


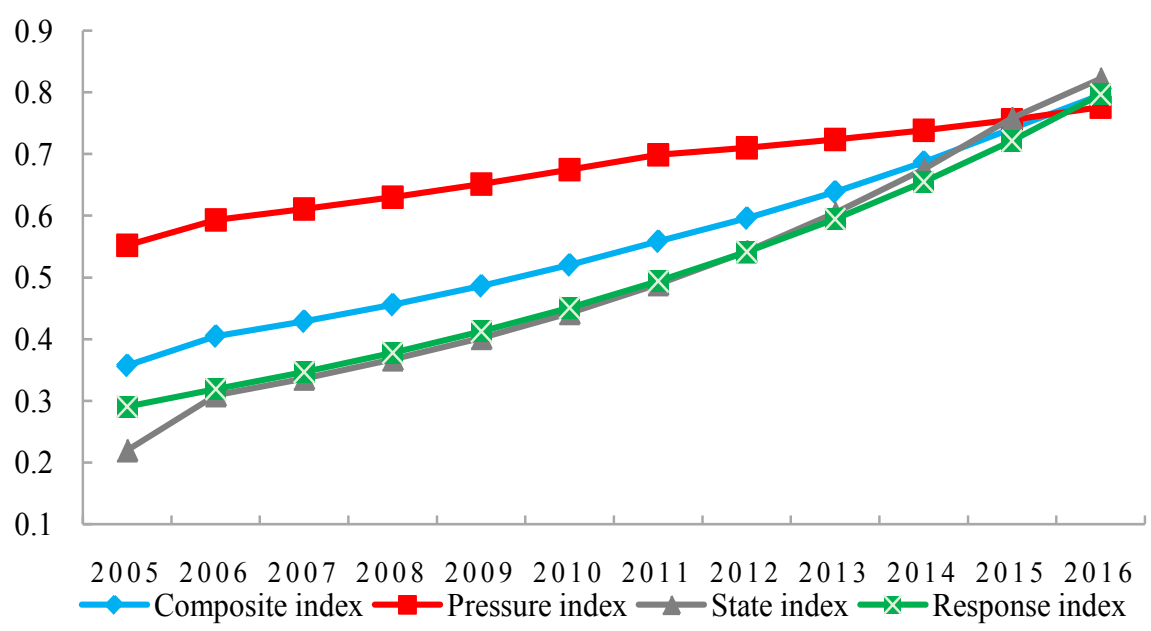

Figure 3. Trends in Guangzhou's entrepreneurship environment composite index, stress index, state index, and response index.

Assessment System, with a view to further exploring the changes and mechanisms of the entrepreneurship environment in Guangzhou.

1) Pressure index

In 2005-2016, although the entrepreneurship pressure index in Guangzhou has risen slowly, it has been at a relatively high level, indicating that the entrepreneurship environment in Guangzhou is under greater pressure. Specifically, it can be divided into two stages. The first stage: in 2005-2015, the entrepreneurship environmental pressure index is greater than the entrepreneurship environment comprehensive index, the entrepreneurship environmental state index, the entrepreneurship environmental response index, and the 2005-2006 pressure index. The slope of the largest is the largest, indicating that the pressure on the entrepreneurship environment in Guangzhou is the largest during this period of time. After that, the slope of the pressure index decreased in 2006-2011, and the slope of the pressure index decreased again in 2011-2016. Although the pressure on the entrepreneurship environment in Guangzhou is increasing, the magnitude of the pressure increase is slowly decreasing. The second stage: in 2015-2016, although the pressure index is still on the rise during this period, the pressure index is already lower than the comprehensive index, the state index and the response index, indicating that the entrepreneurship environmental pressure in Guangzhou has improved, the entrepreneurship environment is getting better and better.

2) State index

In 2005-2016, although the entrepreneurship state index of Guangzhou is very low, it has been in a rapid upward trend, indicating that although the entrepreneurship pressure in Guangzhou is relatively high, the entrepreneurship state is getting better and better. On the one hand, due to the enthusiasm of entrepreneurship in Guangzhou, the number of high-tech enterprises in Guangzhou and the total output value of high-tech enterprises are constantly improving, and the 
achievements of scientific and technological innovation are becoming more and more abundant. On the other hand, with the promotion of the entrepreneurship boom in Guangzhou. The development of the financial industry and the tertiary industry in Guangzhou is getting better and better. Specifically, it can be divided into two stages. The first stage: in 2005-2006, although the state index is very low, the 2005 state index is only 0.220 , but the slope of the 2005-2006 state index is large, indicating The state of entrepreneurship changed at the fastest rate during this time period. The second stage: 2007-2016, although the slope of the state index curve has decreased, it still maintains a relatively fast growth trend, and in 2016, the state index exceeded the pressure index and response index.

3) Response index

In 2005-2016, although the response index has been on the rise, the response index has been low. Specifically, it can be divided into two stages. The first stage: 2005-2012, the response index is increasing, and the trend of the response index is basically consistent with the trend of the comprehensive index curve, indicating that the response measures of the government and relevant departments have positively promoted the improvement of the entrepreneurship environment. However, between 2006 and 2012, although the trend of the state index curve is basically consistent with the trend of the response index curve, the state index is always lower than the response index. This shows that the government's response to the changes in the entrepreneurship environment has a certain time lag from implementation to effectiveness, and the implementation of policy measures is a process of continuous accumulation and continuation. The second stage: 2012-2016, the comprehensive index and state index have exceeded the response index in this stage, indicating that the government's response measures have already played a very good effect in this stage, and the entire Guangzhou entrepreneurship environment has been greatly improved.

\subsection{Prediction of Guangzhou Entrepreneurship Environment}

In order to further illustrate the development trend of Guangzhou's future entrepreneurship environment, this paper uses $\operatorname{GM}(1,1)$ model to predict each evaluation index. The comprehensive index of the entrepreneurship environment, the pressure index, the state index and the response index are calculated according to the comprehensive factor weighting method for each index value after the prediction. The forecast time span is 2017-2025.

From the simulation results in Table 5, it can be seen that the accuracy level of each index is predicted by the $\operatorname{GM}(1,1)$ model. There are thirteen for the good, three for the qualified, and two for the barely qualified, basically meeting the forecasting requirements.

As shown in Figure 4, the pressure index peaked in 2017, and the Guangzhou Venture Capital Index showed a downward trend from 2017 to 2020, and the pressure index steadily stabilized in 2020-2025. The state index has been slowly rising since 2017. The upward trend of the response index from 2017-2020 is 
Table 5. Simulation accuracy values of various indicators of the entrepreneurship environment.

\begin{tabular}{ccccc}
\hline Indicator number & $\mathrm{C}$ & $\mathrm{P}$ & Relative error \% & Accuracy level \\
\hline C1 & 0.274 & 1 & 2.569 & Good \\
C2 & 0.284 & 1 & 13.197 & Good \\
C3 & 0.129 & 1 & 4.948 & Good \\
C4 & 0.683 & 0.79 & 1.175 & Barely qualified \\
C5 & 0.104 & 1 & 2.706 & Good \\
C6 & 0.158 & 1 & 3.764 & Good \\
C7 & 0.505 & 0.75 & 5.481 & Barely qualified \\
C8 & 0.184 & 1 & 7.857 & Good \\
C9 & 0.136 & 1 & 7.030 & Good \\
C10 & 0.435 & 0.88 & 13.976 & Qualified \\
C11 & 0.122 & 1 & 6.026 & Good \\
C12 & 0.198 & 1 & 4.823 & Good \\
C13 & 0.095 & 1 & 4.121 & Good \\
C14 & 0.257 & 1 & 11.148 & Good \\
C15 & 0.401 & 0.93 & 17.525 & Qualified \\
C16 & 0.437 & 0.92 & 9.039 & Goodified \\
C17 & 0.106 & 1 & 1.142 & 2.427 \\
C18 & 0.300 & 1 & & Good \\
\hline
\end{tabular}

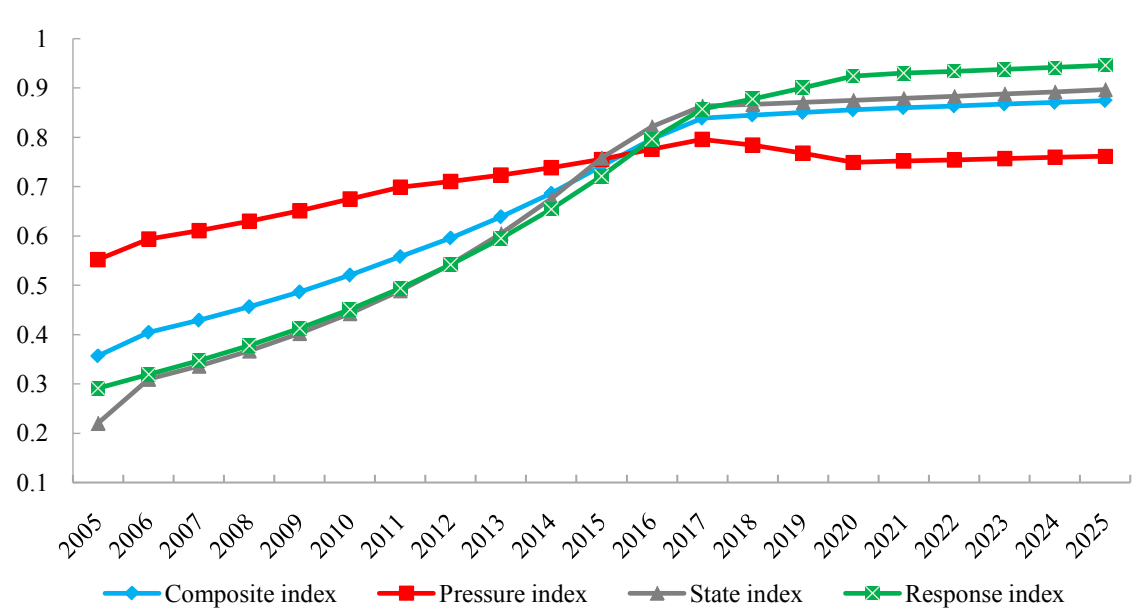

Figure 4. Guangzhou entrepreneurship environment forecast trend chart.

greater than that of the state index. After 2020, the response index is in a slow upward trend, and the increase is similar to the state index. In 2017-2025, the composite index and the state index maintained a similar upward trend. According to the review, since 2016, with the continuous improvement of government response measures, the overall situation of the entrepreneurship environ- 
ment in Guangzhou is getting better and better, and the pressure index of the entrepreneurship environment is getting smaller and smaller. Judging from the overall trend of real value and predicted value, in 2005-2025, the pressure of the entrepreneurship environment in Guangzhou showed a process of rising first, then falling and then stabilizing. The response index of the entrepreneurship environment first rose rapidly and then stabilized. In the "S" state, combined with the state index, the government's response measures have a lagging response. It shows obvious results in 2013-2017. After the entrepreneurship state index maintains a good level, the government must strengthen the response measures. This shows that in the process of sustainable development in Guangzhou, when the urban entrepreneurship environment reaches a certain level, the government's good policy is the core measure to maintain social development. These include research and development funding, education spending, social security and employment expenditures, transportation, and Internet infrastructure.

\section{Conclusions and Policy Recommendation}

\subsection{Conclusions}

Based on the PSR (Pressure-State-Response) model framework, this paper constructs an index system for urban entrepreneurship environment evaluation, selects relevant statistical data of Guangzhou from 2005 to 2016, and systematically quantitatively analyzes urban entrepreneurship policies, service systems, and hardware facilities. And comprehensive evaluation, based on the evaluation and analysis, the $\operatorname{GM}(1,1)$ model is used to predict the development trend of urban entrepreneurship environment in Guangzhou, as shown in Figure 4. This paper draws two conclusions:

First, the current situation of the entrepreneurship environment in Guangzhou has the following characteristics: 1) The response measures of the urban government department to optimize the entrepreneurship environment have certain effects; 2) The government's optimization of the entrepreneurship environment is a process of continuous renewal and accumulation; 3 ) There are certain time lags in the process of optimizing the entrepreneurship environment from implementation to production. To further optimize the regional entrepreneurship environment, it is necessary to carry out policy innovation and management innovation, and open up a new space for the optimization of the entrepreneurship environment at a higher level. Therefore, the response to optimizing the entrepreneurship environment is also a spiraling process.

Second, based on the trend of the comprehensive index, the government's response measures are the core factor of the stable development of the urban entrepreneurship environment. The policy effects accumulated by the policies and measures to improve the entrepreneurship environment in the early stage are gradually released, and the government departments are still introducing new policies. Measures, it is expected that the entrepreneurship environment in Guangzhou will continue to improve in the future. 


\subsection{Policy Recommendation}

Based on the research results, this paper proposes the following recommendations:

First, it is to strengthen innovation and lead the way to stimulate entrepreneurship vitality. The optimization effect of innovation on the entrepreneurship environment is not only reflected in the promotion of entrepreneurship activities, the increase in the number of entrepreneurship activities, the realization of quantitative changes, but also in its ability to improve the success rate of entrepreneurship activities, improve the quality of entrepreneurship activities, and achieve a qualitative leap. The government should start to support innovation from three aspects: First, create a social and cultural atmosphere that advocates innovation. The second is to encourage innovation and research and development, and promote the transformation of innovation results. The third is to improve the patent application system and strengthen the legal protection of intellectual property rights.

Second, it is to gather talents and realize entrepreneurship dynamism. The accumulation of talent advantage will boost the vitality of regional entrepreneurship. Therefore, gathering local talent advantage is one of the important measures for the government to promote entrepreneurship. The government can start to introduce relevant policy measures from two major aspects: First, the incentive policy for the talent group, that is, directly giving the talents their own preferential policies. The second is to introduce incentive policies and measures for talent introduction enterprises and enterprises with core talents.

Third, it is to build a diversified financial service, vigorously promote an entrepreneurship economy, and support entrepreneurship development. The government should accelerate financial system reform, focus on innovation in financial support policies, and improve the efficiency of financial services and entrepreneurship economic development while increasing financial support and introduce and cultivate angel investment. New financing models are supported such as crowd funding crowd sourcing and internet finance. SMEs and microenterprises are provided with financial policies and support that are appropriate to their development phase. In the practice of optimizing the entrepreneurship environment, the government should fully consider the role of the regional economy in promoting the entrepreneurship environment and entrepreneurship activities, give full play to the industrial agglomeration effect, and gradually form an entrepreneurship economy with regional characteristics. The entrepreneurship economy is part of a quality entrepreneurship environment. It will stimulate more regional entrepreneurship vitality, and the occurrence of entrepreneurship activities will in turn boost regional economic development, thus forming a virtuous circle.

\section{Acknowledgements}

This project was supported by the Fundamental Research funds for Central 
Universities, China University of Geosciences (Wuhan) (1810491T09) and Laboratory Research Funds, China University of Geosciences (Wuhan) (SKJ2018240).

\section{Conflicts of Interest}

The authors declare no conflicts of interest regarding the publication of this paper.

\section{References}

[1] Thurik, R. and Dejardin, M. (2013) The Impact of Culture on Entrepreneurship. European Business Review, 6, 57-59.

[2] Bowen, H.P. and Clercq, D.D. (2008) Institutional Context and the Allocation of Entrepreneurship Effort. Journal of International Business Studies, 39, 747-767. https://doi.org/10.1057/palgrave.jibs.8400343

[3] Djankov, S., Porta, R.L. and Shleifer, A. (2002) The Regulation of Entry. Quarterly Journal of Economics, 117, 1-37. https://doi.org/10.1162/003355302753399436

[4] Stel, A.V., Storey, D.J. and Thurik, A.R. (2007) The Effect of Business Regulations on Nascent and Young Business Entrepreneurship. Small Business Economics, 28, 171-186. https://doi.org/10.1007/s11187-006-9014-1

[5] Sambharya, R. and Musteen, M. (2014) Institutional Environment and Entrepreneurship: An Empirical Study across Countries. Journal of International Entrepreneurship, 12, 314-330. https://doi.org/10.1007/s10843-014-0137-1

[6] Autio, E. and Rannikko, H. (2016) Retaining Winers: Can Policy Boost High-Growth Entrepreneurship? Research Policy, 45, 42-55.

https://doi.org/10.1016/j.respol.2015.06.002

[7] Castaño, M.S., Méndez, M.T. and Galindo, M.Á. (2016) The Effect of Public Policies on Entrepreneurship Activity and Economic Growth. Journal of Business Research, 69, 5280-5285. https://doi.org/10.1016/j.jbusres.2016.04.125

[8] Castañomartínez, M., Méndezpicazo, M. and Galindomartín, M. (2015) Policies to Promote Entrepreneurship Activity and Economic Performance. Management Decision, 53, 2073-2087. https://doi.org/10.1108/MD-06-2014-0393

[9] Romanelli, E. (1989) Organization Birth and Population Variety: A Community Perspective on Origins. In: Research in Organizational Behavior, JAI Press, Greenwich, CT, 211-246.

[10] Specht, P.H. (1993) Munificence and Carrying Capacity of the Environment and Organization Formation. Entrepreneurship Theory \& Practice, 17, 77-77. https://doi.org/10.1177/104225879301700207

[11] Gnyawali, D.R. and Fogel, D.S. (1994) Environments for Entrepreneurship Development: Key Dimensions and Research Implications. Entrepreneurship Theory \& Practice, 18, 43-62. https://doi.org/10.1177/104225879401800403

[12] Singer, S., Amorós, J.E. and Moska, D. (2014) Global Entrepreneurship Monitor 2014 Global Report. Executive Report, 3, 66-70.

[13] Cai, L. and Shan, B.N. (2013) Entrepreneurship Research in China's Situation: Retrospect and Prospect. Management World, No. 12, 160-169.

[14] Mai, Y. (2008) Influence of Entrepreneurship Environment on Entrepreneurship Opportunities and Capacities: an Empirical Research Based on Chinese Gem Data. Chinese Journal of Management, 5, 274-278.

[15] Zheng, Y.H. and Zheng-Hui, L.I. (2015) Research on the Effectiveness of China's Financing Service for Technology Innovation. China Soft Science, No. 7, 127-136. 
[16] Zhang, L.W. (2016) Directing Innovation and Entrepreneurship with the Sixth Industry Theory. China Soft Science, No. 1, 1-5.

[17] Tian, Y. and Wang, Z. (2016) A Discussion about the Influence of Informal Institutional Factors on Entrepreneurship. China Soft Science, No. 3, 24-34.

[18] Xie, X.Q. and Huang, J.J. (2017) An Evaluation Analysis of Urban Entrepreneurship Environment Based on PSR Model: Case of Wuhan. China Soft Science, No. 2, 172-182. 